\title{
Medical recipe collections
}

\section{Lehto, Anu Elina}

John Benjamins

2019

Lehto , A E \& Taavitsainen , I A J 2019 , Medical recipe collections . in I Taavitsainen \& T Hiltunen (eds), Late Modern English Medical Texts : Writing medicine in the eighteenth century . John Benjamins , Amsterdam , pp. 279-288 . https://doi.org/10.1075/z.221.11.3.taa

http://hdl.handle.net/10138/325389

https://doi.org/10.1075/z.221.11.3.taa

acceptedVersion

Downloaded from Helda, University of Helsinki institutional repository.

This is an electronic reprint of the original article.

This reprint may differ from the original in pagination and typographic detail.

Please cite the original version. 


\section{Medical recipe collections ${ }^{1}$}

\section{Irma Taavitsainen \& Anu Lehto}

\section{Chronological coverage}

The category of MEDICAL RECIPE COLLECTIONS contains a selection of 23 texts and covers the whole century: the first text comes from 1701 (Thomas Willis, Receipts for the cure of all distempers), and the last two from 1795 (Mrs. Taylor's family companion by Margaret Taylor and William Randall, Medical observations). Detailed information about recipe publication in Britain is available about the first decades of the century: recipe collections made up about 22 per cent of all medical texts in the period from 1640 to 1730 (Fissell 2007: 116-117). No such information is, however, available about the rest of the century. When considered in terms of book circulation at the time, assuming an average age of 30 years per book, the estimation means one recipe book for every four households; yet there is evidence of much longer use over the whole century (Fissell 2007: 114).

\section{Overview of the category}

Understood in a broad sense, recipe collections cover both traditional recipes in a conventionalized form, instructing how to prepare and how to use medicines, and other texts with similar but somewhat more varied contents. The scope of recipes in the printed collections that form the data in our corpus is wide, extending from authoritative compendia to household books with miscellaneous medical and culinary recipes, sometimes even veterinary advice and practical tips, compiled for print on a more ad hoc basis. These published collections reflect middle-class and elite audiences, even though they often contain remedies garnered from across the society, including vernacular remedies that were also disseminated orally. Texts on medical substances and some recipes are also found in other text categories. Following the categorization principles we have used, texts on therapeutic substances that served as medicines, like opium, tobacco, or snuff, are placed in SPECIFIC TREATISES:

\footnotetext{
${ }^{1}$ Ville Marttila has been mainly responsible for the text selection of this category. We are grateful to Alun Withey for his comments on an earlier version of this article.
} 
THERAPEUTIC SUBSTANCES and recipes that have been embedded into longer treatises are found in their respective categories, most often in SPECIFIC TREATISES: DISEASES and in SURGICAL AND ANATOMICAL TEXTS.

Our text selection shows the advent of institutional books in the early decades, i.e. Banyer's Pharmacopoeia pauperum: or, the hospital dispensatory (1718), Quincy's Pharmacopoia officinalis \& extemporanea: or, a compleat English dispensatory, in four parts (1718), Browne's Antidotaria; or, a collection of antidotes against the plague, and other malignant diseases (1721), Hermann's Materia medica (1727), and Gaubius's A complete extemporaneous dispensatory (1741). They mostly represent learned medicine for professional use by university-trained physicians, adjusted to the needs of newly founded institutions that often had to cope with financial restrictions and rely on inexpensive medical ingredients. These texts display aspects of the social developments within the official and public side of medicine in the first half of the century.

The primary arena for both prophylactic and curative healthcare was, however, the household, and the home was the main locus for the care of the sick (see Chapter 5 in this volume). Some recipe collections belong to the more ephemeral kind, but in general, lay medical works became part of the new print culture that appealed to the newly literate layers of society. The domestic realm is represented by several recipe compilations with useful family remedies, often together with cookery advice. Their contents focus on medicines against fairly common ailments, like the bite of a mad dog, worms, colds, and other discomforts (also discussed in letters to the Editor in the GM; see Chapter 7 in this volume). Towards the end of the period, medical chests with suitable components and products for medication became necessary equipment for navy and army doctors as well as large households, and lists of their medical ingredients were circulated in print. LMEMT records two texts with such lists that were indispensable in their own time: Friendly physician by Francis Spilsbury (1773, included in PUBLIC HEALTH) and Medical observations by William Randall (1795).

\section{Authors and audiences}

Medical recipe collections from the eighteenth century represent a fairly wide scale. The learned end is represented by several institutional collections. Some of them, like Pharmacopoeia pauperum: or, the hospital dispensatory (1718) by Henry Banyer (fl. 
1718-1736), are by physicians. Banyer states that he composed it "for the Poorer Sort of People" (Pharmacopoeia pauperum: or, the hospital dispensatory, 1718: A2), but mentions a host of eminent doctors as its sources: "By the Direction of Dr. Coatsworth, Dr. Mead, Dr. Cade, Dr. Wadsworth, Dr. Hales \&c., and Dr. Quincy”. The recipes are praised as "most cheap and most efficacious Medicines, that the whole Art does supply" (Pharmacopoeia pauperum: or, the hospital dispensatory, 1718: A2v). The motivation for this collection is the common good. The same applies to the other institutional collections like Pharmacopoia officinalis \& extemporanea: or, a compleat English dispensatory, in four parts (1718) by John Quincy and those made for The Royal College of Physicians of London (The dispensatory of the Royal College of Physicians in London, 1721) and The Royal College of Physicians of Edinburgh (The dispensatory of the Royal College of Physicians in Edinburgh, 1727). Likewise, the dedication of Antidotaria; or, a collection of antidotes against the plague, and other malignant diseases by Joseph Browne (1718: A2) reads: "To the most Eminently Learned, The President and Community of the Royal College of Physicians, London". A professional audience is also referred to by Robert Dossie in his book The elaboratory laid open (1758). He defines the target group as "those who prescribe or administer medicines, as well as to those who prepare or sell them" (1758: vi). The text then continues with philanthropic aims (see below).

The audiences of medical recipes form a continuum from learned professionals to semiliterate people, though it can be argued that very low levels of literacy precluded the bottom layers of society from accessing these works. The popular end of the market consists of remedy books with the potential for wide appeal to a broad readership of both professional and lay people (see Jenner \& Wallis 2007). ${ }^{2}$ The dissemination of knowledge in this field is, however, extremely complex, and our selection of printed recipe collections overlaps with material that circulated in manuscripts. The border between them was fuzzy: copying both ways was common, and popular recipes in a wide circulation ended up in printed books (see Withey 2011 and Chapter 5 in this volume); and further, book lending took the volumes beyond their intended, primary audience. This fuzziness can be seen in both medical and culinary recipes in A collection of above three hundred receipts in cookery, physick and surgery (1714) compiled by Mary Kettilby and written by "several Hands" (title

\footnotetext{
${ }^{2}$ Evidence for the statement comes from book history, as learned doctors also owned remedy books of the most popular kind (Fissell 2007: 112).
} 
page). The preface explains the motivation for publishing these recipes as well as the compiler's concern for accuracy:

(1) As for myself, I have only to assure the Reader, That as the desire of doing Good, was the sole Motive that at first engaged me in this Work; so has that great Principle ever been too sacred in my Esteem, to suffer the least mixture of Unfaithfulness or Carelessness...

(Kettilby, A collection of above three hundred receipts in cookery, physick and surgery, 1714: A3v-A4)

Most medical books in this period were written by male writers. Collective efforts are gathered in an anonymous collection entitled The complete family-piece (1736). Its contents include "a great Number of Receipts in Physick and Surgery" (1736: 1), as well as miscellaneous useful pieces of instruction and advice for farming, hunting, and fishing, all typically male pursuits. The remedies were collected from "several very eminent and ingenious Gentlemen" (1736: title page) and published for the benefit and service of private families. Similarly, John Theobald's (d. 1760) posthumous remedies (Every man his own physician, 1764) treated various ailments and were reprinted at least in five editions. In household texts, women writers and compilers are exceptionally well represented with four such books, namely those by Mary Kettilby (as above, 1714), Eliza Smith (The compleat housewife, 1728), Mary Cole (The lady's complete guide, 1788) and Mrs. Margaret Taylor (Mrs. Taylor's family companion, 1795). ${ }^{3}$ The last of these recipe collections is intended to "assist the prudent Mistress and her servant" (1795: title page) and shows how integral a role making medicines had in the successful managing of large households and country estates. Typically, the collections contain selections of "most approved receipts" and instructions for miscellaneous domestic tasks, like preserving food for the winter. Some collections are meant for wide use. E.g. the earliest text of the selection, Receipts, begins with praise of the author and continues:

(2) ...the World will be pleas'd to see his Performances

\footnotetext{
${ }^{3}$ Mainly about cookery, although it does include a section on medicine (1795: 150-162).
} 
upon that Subject separated from his other Speculations.

The former are of General Use, and fitted for the meanest Capacities; whereas the latter are only proper for the Learned.

(Willis, Receipts for the cure of all distempers, 1701:

A2-2v)

Charity was a prominent new feature of the century. The increasing imperative to act charitably is reflected in the establishment of infirmaries and dispensaries, but the motivations of helping the poor and those in need of aid are also stated in several recipe collections with rhetorical flourishes and pathetic exclamations, such as "Oh, Heavenly Charity!" (Kettilby, 1714: 4v). The provenance of the recipes can, however, often be traced to learned professional sources:

(3) ...And I am proud to own, that most of the following Prescriptions came from the most Eminent Hands in the Profession. The rest are all Innocent and Safe; and both the one or the other Approved (not from single Instances of Success, but) from a long and repeated Experience.

(Kettilby, A collection of above three hundred receipts in cookery, physick and surgery, 1714: A 6v-7)

The circulation of recipe books was not limited to the capital and principal towns, for it was customary for country estates to collect private remedy collections in manuscript and print them for their own use. Eliza Smith, the author of The compleat housewife (1728) writes under her initials E.S. and summarizes the compiler's role in putting together nearly five hundred recipes of which about two hundred are medical. Some of them had already proved profitable, which points to the incipient consumerism: "they have cured when all other Means have failed; and a few of them, which I have communicated to a Friend, have procured a very handsome Livelihood" (Smith, The compleat housewife, 1728: A5). She includes a homely touch with a humorous statement about how embarrassing it would be to have a book without a preface; it would be as bad as "for a Lady to appear at a Ball without a Hoop-petticoat" 
(The compleat housewife, 1728: A2). This reference gives some text-internal evidence of the target audience who enjoyed a more leisurely lifestyle than people lower down the social scale. Thus, metatextual evidence confirms the intended target group as rich households and gentlewomen, but the role of these ladies as benefactors in the care of the less privileged is also pointed out:

(4) ... for those Generous, Charitable, and Christian Gentlewomen that have a Disposition to be serviceable to their poor Country Neighbours, laboring under any of the Afflicted Circumstances mentioned; who by making Medicines, and generously contributing as occasions offer, may help the poor in their Afflictions, gain their Good-Will and Wishes, entitle themselves to their Blessings and Prayers ...

(Smith, The compleat housewife, 1728: A5)

Thus, remedy collections were not intended only for the housewife taking care of her own family, but for charitable purposes in society. Several other books in their title pages and prefaces also mention women as setting an example to others.

\section{Discourse forms and genres}

Genre conventions of medical recipe writing were established early, and some of them derive from the medieval period. The same basic schemes were maintained in recipes throughout the centuries, ${ }^{4}$ until industry took over medical production from the early nineteenth century on and made home preparation redundant (Jenner \& Wallis 2007: 241; see also Chapter 5 in this volume). Recipes constitute a welldefined procedural genre with clear text type features: headings often contain evaluative adjectives, transitive verbs of a narrow semantic range prevail, and measurements have acquired set forms (see below). The most common way to begin is with the imperative form of the verb take, followed by the ingredients. E.g. a recipe book from 1701 opens with the following:

\footnotetext{
${ }^{4}$ For conventions in medical recipes, see Taavitsainen (2001), Alonso-Almeida (e.g. 2008), and Mäkinen (2011) and for culinary recipes, see Görlach (1992) and Marttila (2014).
} 
(5) Thake a gentle infusion of Senna, Rubarb, yellow Sauders, and salt of Wormwood, in spring Water: next day apply to the wrists the juice of Plantane and Baysalt: Observing a thin Diet during the whole course of the Disease, and Bleeding if the Patient be of a cholerick temperament.

(Willis, Receipts for the cure of all distempers, 1701: 1)

Traditionally, the parts of recipes were well defined and are easy to recognize, but in the eighteenth century the scheme is no longer followed to the same extent as before and the efficacy phrases, for example, did not survive. ${ }^{5}$ Instead, occasional comments such as "'t will blistr, but seldom fails to cure" (an anonymous author's The complete family-piece, 1736: 15) can be found. Medical recipes could also take a freer form of general advice, as the following mid-eighteenth-century example shows:

(6) A Nervous Cholick

128. Use the Cold Bath, daily for a Month: 129 . Or, take an Ounce of Quicksilver, daily for a Month. 130. Or, in Extremity, boil three Ounces of Burdock Seed in Water, which give as a Clyster. $\quad$ (Dossie, The elaboratory laid open, 1758: 41)

The first entry under the title provides a shortcut to the application part - perhaps Cold Bath did not need explanations; the second piece of advice provides another cure with the dosage, and the third includes details of preparation with an indication of how to apply it.

Like the overall organization of recipe collections, the styles of writing show variation, and it is possible to find several modes even within a single text. Mostly the texts are monologic and some contain argumentative passages where the author's voice is heard. Sometimes dialogic questions are posed to the reader, and an

\footnotetext{
${ }^{5}$ Probatum est was a common way of rounding up a recipe in the medieval period (see also Chapter 5 in this volume). Devices like manicules for marking noteworthy passages, deriving from manuscript conventions, were still around in the eighteenth century (Sherman 2007), though not prominent in these collections.
} 
interpersonal mode is present:

(7) What Considerations are rais'd about Bating? What Inquiries are made about our being Immerg' $d$ in Water? What Questions are ask'd about its entering or not entering our Vessels? And what Effects, it may produce by mixing with Liquors in'em? And, Lastly, what may the Difference be in being Immerged in Hot and Cold Water?

(Cockburn, The present uncertainty in the knowledge of med'cines, 1703: 18)

Other interpersonal passages with dialogue between the first and the second person, targeted at the recipient, include "I rest assured...; which I have the vanity to think you will favour..." (Browne, Antidotaria; or, a collection of antidotes against the plague, and other malignant diseases, 1721: A2). An enumerative argumentation strategy derived from learned scholastic writing can be found in Cockburn's The practice of purging and vomiting medicines (1705). This text also makes use of tables and shows a more analytical approach, paving the way towards more modern practices. It is also noteworthy that children's doses are mentioned separately: "we may easily account, by these Tables, for the Doses of Children" (The practice of purging and vomiting medicines, 1705: 7). Marginal notes to the text aid the reader in locating important passages.

\section{Original compositions and translations}

MEDICAL RECIPE COLLECTIONS demonstrate how the common European discourse world of medicine worked. The choice of English rather than Latin is discussed by Quincy, who explains that readers requested an English edition by a trustworthy person to "keep it out of the Hands of those who might not do it Justice" (Pharmacopoia officinalis \& extemporanea: or, a compleat English dispensatory, in

four parts, 1718: 2v). The category contains several translations. The dispensatory of the Royal College of Physicians in Edinburgh (1727) was translated from Latin by Peter Shaw, M.D. Likewise, The dispensatory of the Royal College of Physicians 
(1741) is a translation from the Latin original by "the learned Dr. H. D. Gabius, Present Professor of Physic and Chemistry in the University of Leyden" (1741: title page). The international discourse community is present in another way, too. Several texts build on multiple sources in different languages, e.g. Mary Cole's collection (The lady's complete guide, 1788) uses Buchan's Domestic medicine (1772, included in General treatises), and she also states that Tissot's Avis du People sur la Sainté served as its basis. For further ideas, she has turned to famous domestic authors like Richard Mead and Thomas Sydenham. There is evidence of a two-way traffic as well. William Cullen was an internationally eminent figure, a Fellow of the Royal Societies of Edinburgh, London, Paris, and Madrid, and a member of the medical societies of Copenhagen, Dublin, and Philadelphia. Thus, he belonged to the international elite, and his treatise was "several times reprinted and translated into foreign languages" $(A$ treatise of the materia medica, 1789: 5).

\section{Continuity versus new trends}

Both continuation from the earlier periods and features that partly renew the tradition are present. Alchemy had been an integral part of medicine in the medieval period, and iatrochemical and Paracelsian remedies had gained a firm footing in official pharmacopoeias of the previous century. ${ }^{6}$ The status of alchemy had, however, started to change with the advent of more scientific thinking, and the process went on in the eighteenth century. Dr. Quincy's Pharmacopæia officinalis \& extemporanea: or, a compleat English dispensatory, in four parts continues in the field of "Chymical pharmacy" (1718: 1). This learned collection ran to twelve editions by the midcentury, which shows the strength of this long tradition. Pharmacopeia officinalis \& extemporanea: or, a compleat English dispensatory, in four parts (Quincy 1718) contains sections on vegetable, animal, and mineral medicine, and The dispensatory of the Royal College of Physicians in London (1721) combines chemistry with herbal knowledge.

Materia medica had its roots in medieval herbals and lapidaries and featured prominently throughout the century. An institutional text called The dispensatory of the Royal College of Physicians in Edinburgh (1727) states authoritatively that

\footnotetext{
${ }^{6} \mathrm{Cf}$. the London dispensatory (Culpeper 1649) and the Royal pharmacopoea (Charas 1678), both in EMEMT.
} 
(8) ' $\mathrm{T}$ is universally agreed, that an exact knowledge of the Materia Medica, with the proper manner of preparing and compounding the simples, is absolutely requisite to the due exercise of the Art of Physic, Good Medicines properly administered give assurance of Health..." (The dispensatory of the Royal College of Physicians in Edinburgh, 1727: A2)

Some seventy years later William Cullen published A treatise of the materia medica (1789) and claimed it was virtually a completely new work.

The most conspicuous new feature in this category is the advent of new goals "for a Common Good, and the Publick Health" as advocated in the preface of The dispensatory of the Royal College of Physicians in London from 1721. This collection, and others like it, witness the rise of new charitable ideas and a greater concern for general welfare in society.

The above survey shows that the category of MEDICAL RECIPE COLLECTIONS is fairly broad and contains both conventional features and innovative ideas that renew the tradition. According to Fissell (2007: 121), novel ideas already enter the field by the 1710s, but become even more prominent in the latter half of the century. In 1758, Dossie stated that "I design to make this collection useful ...for the general good of mankind" (The elaboratory laid open, 1758: v). This philanthropic way of thinking finds expression, often explicitly, in several works of this category, but sometimes it is also attested in more subtle ways. Another change, albeit less conspicuous, concerns the attitude towards children. Cockburn (The present uncertainty in the knowledge of med'cines, 1703) takes children into account regarding smaller dosages, and the same applies to Dossie's tables (The elaboratory laid open, 1758), which also give instructions on how to adjust the dosages for children.

Cullen's A treatise of the materia medica from 1789 is one of the last in our selection with a long history section that expresses a critical attitude to inherited wisdom. Instead, he advocates reliance on trials and experience (1789: xi), which is in accordance with the new thought style of the time. He is well aware of historical changes in medicine and writes about the developments with this important insight: 
(9) In assigning the virtues of medicines, I have avoided the compilations which have been so often injudiciously made, ... and commonly without any proper distinction of authorities and probabilities. In this business I have avoided the fault which GALEN imputed to DIOSCORIDES, and which has been the fault of almost every writer on the Material Medica since his time, that is, of ascribing too many virtues to one and the same medicine.

(Cullen, A treatise of the materia medica, 1789: b2)

His choice of words is interesting, as he refers to "probabilities", the basis of modern medicine. This is one of the earliest mentions and can be considered an interesting early signpost towards more modern approaches to medicine. 